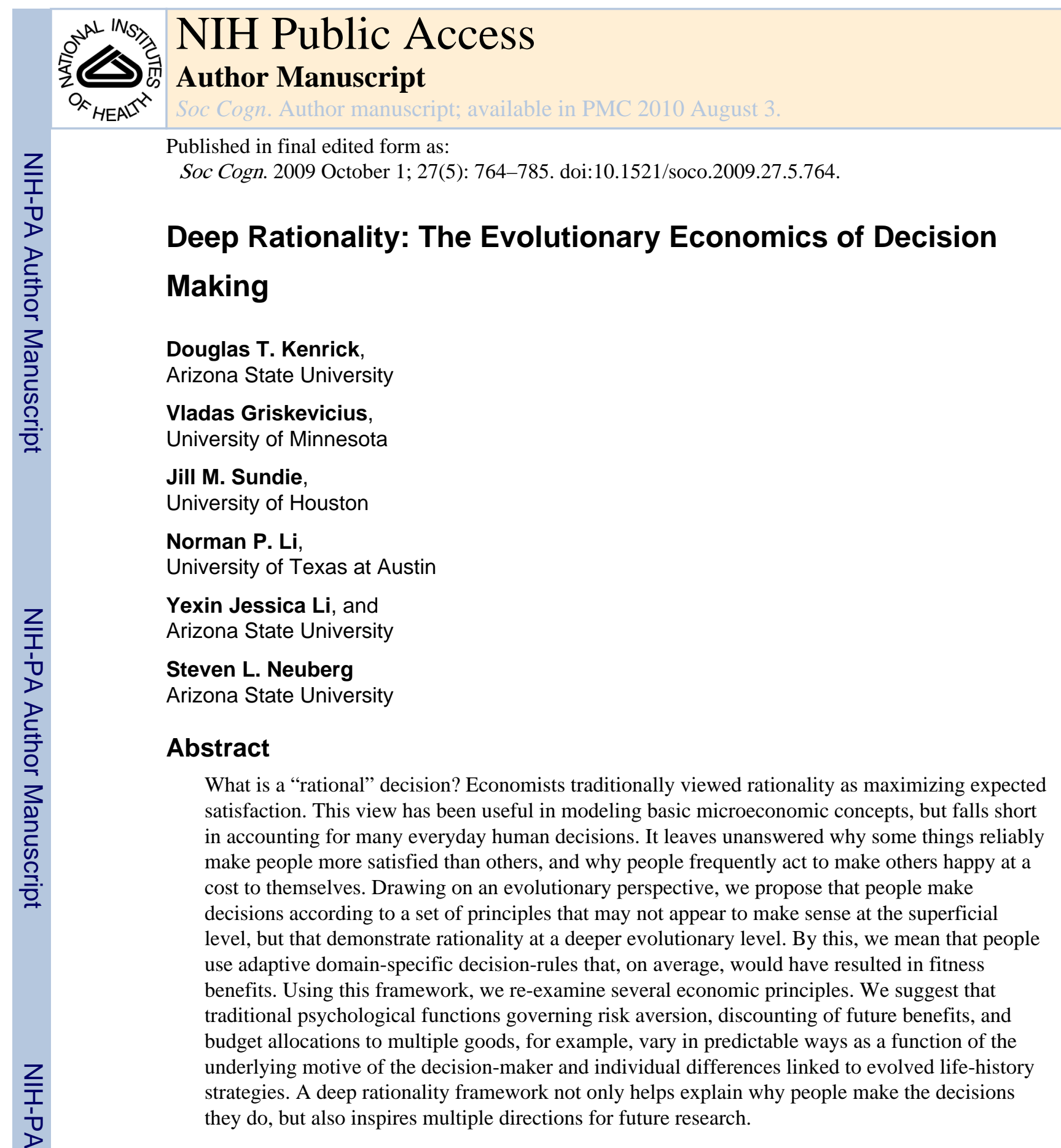

Consider the array of decisions facing a 30-year old MBA graduate just beginning her first full-time management position. In her first days on the job, she will be asked to choose between several investment packages for retirement, with different mixtures of risky versus safe investments. Not long thereafter, she will need to make equally complex decisions about how to invest her scarce time and effort at work (e.g., choosing between various projects, forming alliances with coworkers, impressing superiors, managing subordinates), and in her personal life (e.g., finding a romantic partner, spending time with friends and family, starting her own family) as well as making decisions about how to make trade-offs between work and personal life. Such decisions are fundamentally microeconomic, in that they involve an individual's allocation of limited resources. Traditionally, microeconomic decisions have been modeled on broad notions of rational choice whereby entities attempt to maximize their utility, or expected satisfaction (e.g. Bronfenbrenner, Sichel, \& Gardner, 1990; Mas-Collel, Whinston, \& Green, 1995). 
In what follows, we suggest an expanded, evolutionarily-informed view of rationality that utilizes classic economic tools and also takes into account recent theory and findings at the intersection of evolutionary biology and cognitive science. Evolutionary approaches are inherently economic in nature, focusing on individuals' allocation of scarce resources to various fitness-relevant activities. A key assumption of the evolutionary perspective is that the human brain contains not one monolithic "rational decision-making device," but rather a number of different decision-systems, each operating according to different rules. Which system is currently doing the decision-making depends on adaptively relevant features of the current environment, as well as on the decision-maker's sex, mating strategy, and phase in the life-cycle, among other factors.

We re-examine several general principles of economic psychology in light of this view of rationality. We suggest that traditional psychological functions governing risk aversion, discounting of future benefits, and budget allocations to multiple goods, for example, vary in predictable ways as a function of which fitness-relevant domain is being prioritized.

Specifically, we explore how such economic choices might differ depending on whether the decision-maker is currently considering issues of status, mate acquisition, mate retention, friendship, self-protection, or kin-care. We further suggest that the effects of these motivational influences will vary depending on specific individual differences, such as the sex and age of the decision-maker. In sum, we suggest that a consideration of recent developments in evolutionary psychology can fruitfully expand our understanding of the economic psychological study of everyday decisions.

\section{Economic Rationality}

Theories of rationality have provided a powerful framework for the modeling of microeconomic decisions (e.g., Kreps, 1990). From this perspective, preferences and resource allocation decisions are characterized as utility maximizing functions. "Utility" translates loosely into expected satisfaction (Bronfenbrenner et al., 1990). Utility-based theories of rational decision-making have a number of conceptually useful features. For example, such models make it possible to translate conceptually vague preferences into quantifiable units. Qualitatively different preferences can be equated by converting them into a common currency of utility units, often called "utils," making it possible to compare the value of apples, oranges, computers, cars, or any other commodity. More generally, such models provide a parsimonious mathematical basis for representing people's preferences and resource allocation decisions.

Over the years, microeconomic theories of utility optimization have been revised to take into account some of the constraints facing human minds, including costs of obtaining information and limits in computational ability (e.g., Gigerenzer \& Selten, 2002). Some researchers have suggested that, given those various constraints, decisions resulting from optimization may not be as effective as those achieved by computationally simpler heuristics (e.g., Gigerenzer, Todd, \& the ABC Group, 2002; Simon, 1957).

Whereas some economic theorists have assumed that each person's preferences are idiosyncratic, others have argued that such variations arise because people incorporate considerations of other people's welfare into their preferences (e.g., people with children might get greater satisfaction from benefits accruing to their children rather than to themselves; e.g., Becker, 1981). For example, one person may be willing to spend a great deal for tickets to the opera and dinner dates in expensive restaurants, whereas another may prefer to spend the same large sum on a home security system to protect his or her children. Economic theorists have not generally been concerned with the origins of such otherconcerns (Bergstrom, 1996). More generally, although economic theorists have considered 
various constraints and advanced various refinements on the traditional model, most have remained relatively agnostic about the roots of utility.

Granted, the purpose of microeconomic models has been to mathematically represent basic elements that underlie aggregate preferences and choices. In this regard, the models have been extremely useful. Furthermore, psychologists studying complex decision-making have noted the benefits of such quantitative models (e.g., Erev \& Cohen, 1990; Kenrick \& Sundie, 2007; Mellers, Hertwig, \& Kahneman, 1991). Nevertheless, a consideration of the functional origins of preferences could expand the explanatory power of such models.

To leverage the modern developments at the interface of evolutionary biology and cognitive science as well as the benefits of basic quantitative models, we propose adopting an expanded view of economic rationality that incorporates theoretically-grounded variations in preferences across individuals and contexts. Such a view can clarify the nature of individual differences in preferences and lead to a greater understanding of the domain-specific objectives, contextual inputs, and decision rules that underlie people's actual preferences and choices. Importantly, the approach we will outline has extensive implications, suggesting new hypotheses about previously unexplored regions of human decision-making.

\section{Evolutionary Economics: Utility = Fitness}

Why do some things have utility for most people, and others not? Although people differ from one another in their patterns of preferences, most place high value on certain social commodities, such as spending time with good friends, eating good food, getting praise from their bosses, being kissed by an attractive romantic partner, or being hugged by their children. Understanding the roots of utility could allow a richer understanding of many key resource-allocation choices people make. Some economists have turned to recent developments in evolutionary biology, and advanced the simple assumption that utility = fitness (e.g., Gandolfi, Gandolfi, \& Barash, 2002). In biological terms, "fitness" refers roughly to an organism's capacity to get its genes into the next generation, either by producing its own offspring or by helping relatives reproduce. Evolutionary biologists assume that the mechanisms driving all organisms' choices are ultimately designed to maximize fitness. This suggestion implies that choices are not arbitrary, but are sensibly connected to important biological goals.

Our approach to decision-making follows up on the general idea that fitness = utility. However, we believe that appealing generally to "fitness" is not itself specific enough (c.f., Aktipis \& Kurzban, 2004). What serves a person's fitness varies depending on several biologically relevant factors, including the person's stage of life history, current ecological factors (linked to psychology via currently activated motives), and individual differences in mating strategy (itself an interactive function of innate and past ecological factors). In particular, two key sets of concepts from modern evolutionary theory suggest systematic variations in human preferences. One is the concept of functional modularity or domainspecificity: Modern evolutionary theorists, following on findings from cognitive science, presume that the human brain does not operate as one large central processing unit but instead solves different adaptive problems using relatively independent functional modules (e.g., Barrett \& Kurzban, 2006; Kenrick, Sadalla, \& Keefe, 1998). In other words, the notion of modularity presumes that there are domain-specific decision-rules, which are themselves activated by distinct inputs and which produce specialized outputs for different problems of social living (e.g., Kenrick, Li, \& Butner, 2003; Schaller, Park, \& Kenrick, 2007). Such domain-specific modules favor fitness-enhancing choices, yet may produce morphologically very different behaviors in different contexts. People do not make decisions using the same 
criteria in interactions with their children, their mates, their friends, and their superiors (Ackerman, Kenrick, \& Schaller, 2007; Fiske, 1992; Kenrick, Sundie, \& Kurzban, 2008).

Another key set of evolutionary concepts comes from life-history theory, developed by behavioral ecologists to understand the critically different trade-offs organisms face at different life stages. For example, early growth, mating, parenting, and grandparenting involve acquiring and spending different resources according to different sets of natural priorities (Kaplan \& Gangestad, 2005; Kenrick \& Luce, 2006). We discuss both sets of key ideas in more detail below.

\section{Domain Specificity and Deep Rationality}

The assumption that people are motivated by a general desire to maximize utility, or the related idea that organisms are motivated to "seek reward" and "avoid punishment," are two examples of "domain general" approaches to understanding behavior. Such views initially appeal to parsimony, but an abundance of research on learning and cognition has posed problems for these "one mind - one process" approaches (Sherry \& Schacter, 1987; Tooby \& Cosmides, 1992). Instead, people and other organisms seek different kinds of pleasure and avoid different kinds of punishment using very different, and sometimes completely incompatible, rules.

Zoologists and comparative psychologists have uncovered a wealth of specialized behavioral and cognitive mechanisms peculiarly suited to the demands of particular species (Alcock, 2005). Consider mechanisms for learning avoidance to poisonous foods, which do not follow the same rules as other learning mechanisms (Rozin \& Kalat, 1971). Whereas some learning requires instantaneous feedback (e.g., it is important that we feel pain immediately after touching a hot stove to learn not to touch it), people and other animals can learn to avoid foods that made them sick many hours after the food was eaten. Learning aversion to foods is also unlike many other types of learning, in that it requires only one trial and is difficult to extinguish. Furthermore, the types of stimuli that get conditioned to nausea vary in ways consistent with an organism's evolutionary history and typical ecology. For example, rats, which have poor vision and rely on taste and smell to find food at night, easily condition aversions to novel tastes, but not to novel visual stimuli (Garcia \& Koelling, 1966). Quail, on the other hand, which have excellent vision and rely on visual cues in food choice, show the opposite bias, conditioning easily to visual cues but not to taste (Wilcoxon, Dragoin, \& Kral, 1972).

Much research demonstrates that humans have different domain-specific systems for dealing with different types of adaptive problems, including learning aversions to different types of objects, language learning, long-term memory for different types of objects, facial recognition, spatial location, object perception, and fear conditioning (e.g., Barrett \& Kurzban, 2006; Domjan, 2005; Klein, Cosmides, Tooby, \& Chance, 2002; Sherry \& Schacter, 1987). For example, people show adaptive biases in visual detection for different types of objects. People are much faster and more accurate at detecting objects that posed threats in ancestral environments (e.g., predatory animals) than at detecting objects that pose threats only in modern-day environments (e.g., fast-moving vehicles) (New, Cosmides, \& Tooby, 2007). Better detection for predatory animals than for other objects-even dangerous objects that we are taught to be wary of from early age—-suggests a domain-specific monitoring system tuned to ancestral rather than to modern priorities. Similarly, people show domain-specific biases in fear conditioning. Fear is much more easily conditioned to objects that resemble snakes or spiders - objects that posed a significant threat throughout our evolutionary past - than to electrical outlets or automobiles - objects that cause many more deaths in current-day environments, but which did not exist in our evolutionary past 
(Öhman \& Mineka, 2001). The fact that people are prepared to learn to fear specific types of objects that posed harm in ancestral environments suggests that we are equipped with specialized mechanisms.

To acknowledge domain-specificity is not to argue for a genetic determinist viewpoint. Indeed, to be adaptive, the different systems involved in varying types of information must be flexible and sensitive to environmental inputs. For example, the human language capacity meets most criteria for a domain-specific cognitive system, yet it clearly requires flexibility. To exercise the human capacity for language, people need to be exquisitely sensitive to environmental inputs - to learn which sound sequences comprise the particular language spoken in their local community (Pinker, 1994). Similarly, although responses to threats (such as spiders, snakes, and snarling dogs) are processed according to rules specialized in ways very different from those governing language acquisition, the fear system also involves flexible (and in this case, very rapid) learning of which stimuli to associate with danger (Öhman \& Mineka, 2001).

The implication of the work on domain-specificity is that although it may make some sense to try to equate different kinds of utility, the human brain does not equate them, and in fact responds to different kinds of utility using different cognitive processing rules, and applies those rules in flexible, but predictable, ways across different contexts. Thus, whereas the idea that utility $=$ fitness suggests that human decision-making is geared to maximize fitness generally, the idea of deep rationality suggests human decision-making is geared specifically to solve recurring adaptive problems in different domains, whereby successful solutions to such problems are associated with increased fitness. The notion of deep rationality builds on previous work showing that human decision biases can be better understood by considering the ecological context for which such biases evolved (e.g., Gigerenzer, 2000; Haselton \& Nettle, 2006).

\section{Life History, Sexual Selection, and Differential Parental Investment}

Animals exhibit a variety of reproductive life histories. Some animals start reproducing shortly after birth and produce thousands of offspring, whereas some wait decades and produce only a handful; some animals devote no effort whatsoever to caring for their progeny, whereas others sacrifice the bulk of their own bodily resources, and sometimes their lives, to protecting and nurturing their young. Studying the array of unique adaptations found across the animal kingdom has uncovered several general principles governing the evolution of diverse traits, as well as some recurring linkages between those traits and environmental constraints and opportunities. One powerful set of principles is embodied in life history theory, which assumes all organisms must resolve a key set of trade-offs throughout their lives (Kaplan \& Gangestad, 2005; Kenrick \& Keefe, 1992). Central tradeoffs involve allocating energy to development versus mating versus parenting. For example, effort spent on attracting mates is effort that cannot be spent on caring for young. Depending on ecological factors, different animals allocate effort differently across their life-spans. Some fish, for instance, change from small drab females into large colorful males if a territory becomes available; some animals (such as salmon) reproduce in a single grand effort, whereas others (such as elephants) reproduce repeatedly over their life-spans.

Within any given species, females and males often have different life histories. Part of the reason has to do with differential parental investment, which refers to one sex contributing relatively more to rearing offspring, discrepancies that in turn carry a number of important consequences for mating choices and competition within a sex. When there is a difference in the amount of parental investment, it is more commonly females who provide greater amounts of offspring care. In mammals, for example, females carry the young inside their 
bodies and nurse them after they are born. Because mammalian females always pay a high price for reproduction - whereas males may contribute little or nothing to offspring carefemales are relatively more selective in their choice of mates (Trivers, 1972).

Individual members of the sex investing less in offspring tend to compete with one another for mating opportunities with the higher-investing sex. Thus, differential parental investment is intrinsically linked to sexual selection, which refers to the relative evolutionary success of traits that assist in mating (by helping either to attract the opposite sex or to compete against members of one's own sex). Darwin developed the idea of sexual selection to address the fact that some adaptations result in one sex being larger, more colorful, and more competitive than the other. Sexual selection is the process by which peacocks developed their bright feathers: although energetically expensive to produce and maintain, the displays increase the males' chances of attracting peahens. Ostentatious feathers are found in peacocks and not peahens because the females make a greater investment in the offspring, and are therefore choosier about their mating partners (who must consequently compete to be chosen).

Thus, the theories of sexual selection and differential parental investment are useful in understanding sex differences, which are expected to change in predictable ways depending on the stage of an individual's life-history. One key implication from life history theory is that men and women will have intrinsically different utility functions for some categories of benefits, and that what is deeply rational for a female is not always deeply rational for a male. Another possible implication for humans is that, even within a sex, different people will have different utility functions if they are enacting different mating strategies.

\section{A Modular View of Utility}

Our general argument thus far is that there may be important implications of domainspecificity and life-history theory for "rational decision making." The notion of deep rationality suggests that different decision rules will apply to different kinds of cognitive inputs. A complementary implication is that complex social situations will be processed very differently depending on which fundamental motivational systems are currently active. If a woman enters a room full of people, she will attend to, remember, and behave very differently if she is concerned about threats to physical safety as compared to finding a romantic partner (e.g., Griskevicius, Goldstein, et al., 2006; Kenrick, Delton, Robertson, Becker, \& Neuberg, 2007; N. Li, Halterman, Cason, Knight, \& Maner, 2008; Maner et al., 2005, Neuberg, Kenrick, Maner, \& Schaller, 2004; Schaller et al., 2007). Still other information will be salient, and decisions will be made differently, if she is motivated to find a new friend or to advance her status (Ackerman et al., 2007; Maner, DeWall, Baumeister, $\&$ Schaller, 2007). Finally, this approach implies a dynamic interaction between the currently active motivational system and the other people present in the situation. Although an attractive member of the opposite sex may be generally salient, for example, that same attractive target may or may not elicit romantic motivation depending on whether he or she appears to be alone versus is holding hands with someone.

Life-history theory also has implications for the investment of scarce resources, which would be expected to vary in predictable ways with life stage (e.g., whether a person is engaged primarily in searching for mates versus caring for offspring), ecological factors (e.g., sex ratios, availability of mating opportunities, presence of competitors or relatives), and individual differences (e.g., the person's sex and typical mating strategy). We have argued elsewhere that different decision biases involved in human social interactions can be usefully organized into several sets of recurrent challenges and opportunities (Ackerman \& Kenrick, 2008; Kenrick et al., 2003; Neuberg, Kenrick, \& Schaller, 2009). In Table 1, we 
consider the different domains of affiliation, status, self-protection, mate search, mate retention, and kin care-domains which arguably encompass most of the decisions people make in their everyday social lives. We suggest some systematic differences in the "utility" and "disutility" associated with certain fitness-relevant outcomes, consistent with evolutionary principles. For example, priming individuals with the domain of mate search leads them to respond more aggressively to insults (Griskevicius, Tybur, et al., in press). Although physically assaulting someone after an insult is rarely a rational response, the fact that such responses are amplified when mating motives are active is consistent with the deeper rationality underlying human mating (Wilson \& Daly, 1985). Thus, although these types of domain-specific biases are not necessarily reflected in conscious strategic planning, they are nevertheless presumed to be "rational" in a deeper sense.

The biases given as examples in the rightmost column of Table 1 have been discussed in detail elsewhere (e.g., Kenrick, Maner, \& Li, 2006; Schaller, Park, \& Kenrick, 2007). Those decision biases are based on theoretical considerations, but have received some degree of support from empirical research. Such research includes Griskevicius, Goldstein et al. (in press) on conformity under fear motivation; Cosmides and Tooby (1992) on cheater detection; Wilson and Daly (1985) on risky behavior by young unmated males; Becker, Kenrick, Neuberg, Blackwell, and Smith (2007) on rapid detection of anger in male faces; Ackerman et al. (2006) on memory for angry outgroup faces; Griskevicius, Goldstein et al. (2006),Griskevicius, Cialdini, and Kenrick (2006), and Griskevicius, Tybur et al. (2007) on male counterconformity and display vs. female generosity under mating mating motivation, and on female generosity under mating motivation; Dijkstra and Buunk (1998),Gutierres, Kenrick, and Partch (1999), and Kenrick, Neuberg, Zierk, and Krones (1994) on attention to socially dominant men and attractive women; and Laham, Gonsalkorale and von Hippel (2005) on biases in grandparental investment.

When people are actively pursuing one of these social goals (self-protection versus kin care, for example), the focus on that domain evokes processing attunements that lead to decisions (e.g., taking a much longer route home) consistent with achieving that particular goal (avoidance of dark areas at night), but that are not necessarily aligned with other goals (spending more time at home with one's children). Such attunements, consisting of biases in attention, information processing, and decision criteria (e.g., Haselton \& Buss, 2000; Griskevicius et al., in press; Maner et al., 2005), would have led to behaviors with positive fitness consequences for most of human ancestral history.

In the remainder of this article, we consider several aspects of economic decision-making studied by economists and economically oriented psychologists. As we do so, we indicate some ways in which an evolutionary domain-specific approach suggests systematic variations in how such decisions are made.

\section{Diminishing Marginal Utility}

Marginal utility refers to the expected benefit one might obtain from an increase in any given good (the third slice of pizza as compared to the second, for example). For many goods, there is a diminishing marginal utility: the expected benefit of getting 1 slice of pizza as compared to none is greater than the expected benefit of getting 11 slices as compared to 10 , for instance. If one plots a utility function for such a good, therefore, it is not linear, but rather curves downward in typical logarithmic fashion. Figure 1 shows college students' judgments of the marriage value of opposite-sex targets as a function of the targets' income (based on Kenrick, Sundie, Nicastle, \& Stone, 2001). Two things are important to note: First, students perceived greater increases in value in going from potential mates with very low incomes to middle levels of income than they did in going from potential mates with 
middle incomes to high incomes. Second, the curve is steeper for females judging males than for males judging females; women care more about avoiding destitute partners than do males. In contrast, when the same participants judged identical targets as short-term sexual partners, women's judgments of men became less steep (similar to the male line in Figure 1), and men's judgments yielded a poorly fitting and relatively flat function (indicating that males judging women as sexual partners were largely oblivious to those women's income levels).

When one considers the different contributions that men and women make to their offspring under long- versus short-term mating arrangements, these judgments can be seen to reflect rational biases. Women's contributions to their offspring have traditionally involved more direct physiological resources (e.g., pregnancy and nursing), whereas men's contributions have traditionally involved indirect resources (provision of food and shelter), which in modern societies are signaled by one's ability to generate income. Thus, long-term mate value is more likely to increase as a function of income for women judging male partners than for men judging female partners; hence, the curve is steeper for women. In the ancestral past, it is likely that offspring survival depended on having access to a critical minimum level of resources. Though more is better, further amounts beyond the required mimimum likely contributed increasingly less to survival prospects. Thus, the curves flatten as income increases, reflecting diminishing marginal utility of income. In support of this, the value of status has been found to marginally diminish in economics-based research investigating women's preferences for long-term mates (N. Li, Kenrick, Bailey, \& Linsenmeier, 2002).

For short-term sexual partners, women may be less certain of obtaining a portion of a man's resources, and thus seem to place greater emphasis on male features correlated with "good genes" (e.g., symmetry, attractiveness, physical size) (Gangestad, Garver-Apgar, Simpson, $\&$ Cousins, 2007; Little, Jones, \& DeBruine, 2008). On the other hand, because men stand to make very little investment of indirect resources to offspring from short-term mates, they become relatively nondiscriminating (e.g., Gangestad \& Simpson, 2000; Kenrick, Sadalla, Groth, \& Trost, 1990; Li \& Kenrick, 2006). Such considerations are reflected by the flatter female curve and non-fitting male curve when considering potential short-term mates.

As in the case of men and women judging mates and seeking status, we would guess that marginal utility curves will vary depending on a number of factors linked to fundamental motivations and life-history strategy. For example, one might expect that activating the motivation to seek new mates would lead the utility curve for one's own increments in status to flatten at a higher level for men, but not for women (cf. Griskevicius, Cialdini, \& Kenrick, 2006; Roney, 2003).

\section{Risk Aversion versus Risk Seeking}

Most decisions about where to invest one's time and effort involve some degree of uncertainty. For example, although a person will generally get higher payoffs from a risky retirement portfolio, the stock market may crash dramatically. Similarly, the time spent writing a grant proposal or submitting an article to a top journal may not pay off, and the energy invested in getting to know a new romantic partner may not result in a satisfactory long-term relationship. In ancestral environments, people often operated close to the margin, with a serious danger that they, or their children, might not survive if they misjudged how to invest their time and effort.

Evidence from modern groups living in hunter-gatherer or horticultural societies suggests that human beings are generally risk-averse, preferring to invest in activities with relatively low risks as opposed to those with potentially higher, but riskier, outcomes (Winterhalder, 2007). Such "risk aversion" is consistent with a standard observation in market economics 
called "loss aversion." This phenomenon refers to people's stronger preference of avoiding losses than acquiring comparable gains (Kahneman \& Tversky, 1979). Findings on both risk aversion and loss aversion suggest that people, whether in traditional societies or in modern market economies, are cognitively biased to ensure that they do not fall below some minimal threshold of resources necessary for survival (e.g., Wang, 2002).

Figure 2 depicts the psychological differences between gains and losses, as outlined in Kahneman and Tversky's Prospect Theory (Kahenman \& Tversky, 1979, pp. 279). The Xaxis depicts the objective gains (moving from the center zero point to the right) and objective losses (moving from the center zero point to the left). The Y-axis depicts changes in psychological utility (or the changes in expected value or happiness with movements away from the zero point). The solid line depicts the focal difference between losses and gains. For example, an objective loss of $\$ 200$ is expected to produce more psychological change than an objective gain of similar magnitude.

We would expect this function to vary in line with evolutionarily relevant factors. The lighter line in the figure depicts a hypothesized sex difference in decision-making that follows from our earlier discussion. Given findings that mating motivation leads men to display resources and status (e.g., Griskevicius et al., 2007), we might expect men with activated mating motives to be more willing to take financial risks to achieve gains. This risk-taking would serve two main purposes-to impress desirable potential mates and to possibly obtain more resources than would be possible by taking the safer route. Thus, for men in a mating mind-set, winning $\$ 200$ may be as satisfying, if not more so, than losing $\$ 200$ is disappointing (see Figure 2). Women, on the other hand, might not respond the same way to a mating prime, knowing (at least implicitly) that men do not place as much emphasis on women's money and resources when considering them as potential mates (Kenrick et al., 2001). Indeed, women might actually become more risk-averse or lossaverse when in a mating state because females traditionally have more to lose by careless mating choices (e.g., Haselton \& Buss, 2000; Griskevicius, Goldstein, et al., 2006). That is, women might be less risk-seeking with respect to losses, risk-averse with respect to gains, and loss averse in general when in a mating state.

Of course, gains and losses often involve goods that are not typically traded for money, such as friends or attractiveness to the opposite sex. In an ongoing series of studies, we have been asking people to imagine that they could exchange any or all of a windfall $\$ 1000$ for social benefits (e.g., in increase in attractiveness to the opposite sex, new friends, or a gain in status) or to avoid social losses (e.g., a decrease in attractiveness, or loss of friends or status). Preliminary results reveal the typical loss aversion, such that people pay more to avoid a given amount of loss in friendship networks, for example, than they pay for a comparable gain. However, this general loss-aversion bias is not very strong for all social categories, and even reverses itself for males who have been exposed to a short-term mating context (Y. Li, Griskevicius, \& Kenrick, 2008). These are preliminary findings, but an evolutionary perspective leads to the general expectation that relative valuations of gains and losses will vary in important ways as a function of domain-specific evaluations and lifehistory considerations.

\section{Temporal versus Probability Discounting}

Due to their risk aversion, people tend to devalue benefits that are not certain and immediately available. From an evolutionary perspective this makes sense because promised future benefits may never materialize, and because waiting for resources in the future may often result in lost reproductive opportunities (Wilson \& Daly, 2004). These important considerations are consistent with the concept of discounting found in economics. 
Discounting can be separated into two potentially distinct components: temporal discounting (the decreasing valuation of rewards the longer one must wait to receive them) and probability discounting (the decreasing valuation of rewards the less certain one is to receive them) (Green \& Myerson, 2004). In other words, a given benefit (e.g., \$1000) is worth less if you have to wait for it (temporal discounting) and if there is some uncertainty regarding whether or not you will get it (probability discounting).

The classic example of temporal (or future) discounting involves a choice between a larger and a smaller reward, where the smaller reward is available sooner than the larger one. Although an individual may choose the larger, later reward when both alternatives are well in the future, with the passage of time the preference may reverse so that the individual now chooses the smaller, sooner reward. For example, one might prefer to receive $\$ 100$ right now rather than $\$ 120$ one month from now (even though the additional $\$ 20$ in one month would have been equivalent to a 240 percent annualized interest rate on the \$100). A good example of this phenomenon is found among people who win public lotteries. Winners frequently sell their income stream to companies that pay them cash at a huge discount rate - one that greatly exceeds the relatively risk-free rate that underlies the safe government income stream.

It is generally presumed that any given individual has a stable discounting rate. For example, a drug addict is believed to value the present more than a graduate student, who is much more willing to defer gratification, meaning that he discounts the future at a less steep rate. But in at least one experiment, researchers have shown that discount rates within individuals actually vary in ways that reflect sensitivity to evolutionarily relevant stimuli. Wilson and Daly (2004) had participants view attractive members of the opposite sex to activate participants' mating motives, and then had them choose between immediate and delayed rewards (for example, $\$ 25$ today versus $\$ 60$ in 6 months). Men who viewed attractive women tended to shift their preferences toward immediate over delayed rewards (but women who viewed attractive men did not). Wilson and Daly (2004) explained these findings in terms of sex differences in mating strategies. Whereas males stand more chance of improving their fitness from short-term expenditures of mating effort, females are, in line with our earlier discussion of parental investment, more likely to focus on long-term investments. Various forms of archival data are consistent with their analysis, with young men being generally more focused on immediate rewards and more likely to engage in risky behaviors with high immediate payoffs (e.g., Arias, 2002; Kirby \& Marakovic, 1996). This general tendency for young males to take more risk than young females can have long-term economic consequences. Young single men are generally more likely to adopt riskier investment strategies in their retirement packages than are women, and as a result, at retirement time those men tend to have earned, on average, substantially higher yields on their investments (Sundén \& Surette, 1998).

From an evolutionary perspective, temporal and probability discounting may be designed to manage qualitatively distinct types of risk. If so, activating different fundamental motives may influence each type of discount rate in different ways. For instance, activating mating or status concerns should lead men to become less risk-seeking regarding the future (temporal discounting). That is, as mentioned above for mating motives, status motives should also lead men to prefer taking less money now rather than risk their chances to wait for more money in the future (Wilson \& Daly, 2004). But activating the same status or mating motives should lead men to become more risk-seeking regarding probabilistic rewards, meaning that men should be more willing to take risks with their money for potential immediate payoffs. 


\section{Indifference Curves and Spending Budgets: Optimizing Combinations of Benefits}

One aspect of rational decision-making involves allocating one's limited resources to optimal combinations of goods. Indifference curves are a microeconomic concept indicating levels of overall utility that a consumer derives from bundles of goods (brownies and mochas, for example). They are useful for expressing the trade-offs people make between those goods. Each point on an indifference curve consists of a different combination of goods that provides an identical level of overall utility, given the available budget (Eatwell, Newgate, \& Newman, 1987).

Indifference curves and budget constraints can be employed to capture some of the qualitiative shifts in "consumption" that would accompany changes in preferences due to activated motives, or individual differences linked to life-history strategies. For example, a person may place similar value on time spent with a new romantic partner (call that good X) and time spent at work (good Y). As such, one's indifference curves for those two activities may look like Figure 3a. However, after seeing a workmate get promoted, status motives may become activated, causing a shift in one's preferences such that one now devalues romance relative to work; appearing more like Figure 3d. More generally, from the evolutionary perspective of deep rationality, indifference curves will be influenced in reliable ways depending on the social domain that is currently most pressing, in combination with life-history characteristics of the decision-makers. We would expect that the shape of these curves, and their variations across situations, can give important clues about the operation of underlying adaptive psychological mechanisms.

Another way in which to incorporate evolutionary thinking about regularities in people's preferences is to consider what kinds of goods will constitute "necessities" versus "luxuries." When people have nothing and are given a low income, they typically allocate a relatively high proportion of the income toward what is most essential for basic living necessities. However, necessities face diminishing marginal utility, so that if additional income becomes available, it tends to be spent not on additional necessities (e.g., more low quality foods, more electricity), but rather, on luxuries (e.g., fine dining, private education, vacations). Figure $4 \mathrm{~b}$ plots necessities versus luxuries as goods. At low levels of overall utility, indifference curves are steep towards the more valuable necessities $\left(\mathrm{U}_{1}\right)$. However, at higher levels of overall utility, indifference curves shift to being steep towards luxuries $\left(\mathrm{U}_{3}\right)$.

These microeconomic concepts have been used to examine how social psychological choices vary with evolutionarily relevant factors. For instance, Li and colleagues (2002) gave men and women low, medium, and high budgets of "mate dollars" to purchase levels of characteristics pertaining to a potential long-term mate. When budgets were low, men tended to purchase physical attractiveness, whereas women tended to purchase social status and resources. As budgets grew, people spent less on these sex-differentiated characteristics and spent a greater proportion on other characteristics, including creativity.

These findings were consistent with an economically informed evolutionary view of mate choice. Given that ancestral women varied in their ability to bear children, and that features judged in females are related to fertility (e.g., Singh, 1993), it makes sense for males to prioritize obtaining a minimal level of physical attractiveness to increase the odds that a mate is fertile. Similarly, ancestral men varied in their ability to provide essential resources for offspring. In particular, those men with little or no social status may have had little or no access to resources. Thus, it made sense for ancestral females to prioritize obtaining a minimal level of social status to ensure that their mates could provide at least some resources for potential offspring. 
However, as a potential mate demonstrates more than minimal levels of these characteristics, they likely decrease in marginal utility; further gains along these dimensions will increase a mate's reproductive value increasingly less. Thus, when given additional mating income (the ability to afford a mate of higher overall quality), other characteristics become more highly valued. In other words, both sexes would ideally like to have a wellrounded, high-quality mate, if they had a high budget (i.e., if they were themselves a very desirable mate). However, if a person's choices are highly constrained (as they are for most mortals), men prioritize physical attractiveness and women prioritize social status as necessities. Thus, an economic view helps address a debate about whether the sexes are different or similar when it comes to mate preferences (Li \& Kenrick, 2006). As shown in Figure 5, sex differences in mate preferences are relatively large when choices are constrained by a low mating budget (with men favoring physical attractiveness and women favoring resources), but as mating budgets expand and choices are less constrained, sex differences tend to disappear.

The notion of budget constraints is highly useful when examining not just mate preferences, but when investigating any kind of decision-making. After all, individuals not only have different "budgets" of financial resources but they also have different budgets of time and energy that can be spent on different activities. Thus, although a young executive may desire to outshine her peers and become a corporation vice-president in record time, while also cooking healthy dinners for her family every night after picking up her kids from school, time and energy constraints make it unlikely that she will be able to accomplish all these competing goals. Instead, her allocation of time and energy will depend on which particular motives are currently active in combination with life-history considerations. For example, children are well-designed with behaviors that trigger parental care motivations, such that a crying child is likely to redirect any resources away from career concerns. Women with children are acutely sensitive to the specific cries of their own children (Soltis, 2005). This re-allocation of effort might be expected to occur for both parents, but somewhat more readily for females, and any such sex difference ought to be magnified by any factors that reduce paternal certainty (Laham et al., 2005). On the other hand, an active mate acquisition goal would be expected, in line with our earlier discussion, to influence men's allocation of effort to status more than women's.

\section{Conclusion}

Are human beings rational decision-makers in the classic economic sense? On the one hand, the considerations we have raised support a view of people as ultimately quite rational. On the other hand, these considerations also suggest important additions to the traditional economic approach to rationality. For one thing, there are predictable variations linked to adaptive goals and life history that have critically important influences on how people allocate their limited resources, and ignoring those variations leaves us with an incomplete accounting of rational decision-making. For another, the emphasis on goods traded on financial markets may be fine for economists concerned only with aggregate decisionmaking on such markets, but people's everyday decisions about resource allocation involve non-monetary goods and services; instead they involve other people who are not subjected to the same rules that apply between stockbrokers in different trading houses on Wall Street (Clark, Mills, \& Powell, 1986; Fiske 1992; Kenrick, Sundie, \& Kurzban, 2008).

Furthermore, particular aggregations of individuals under particular evolutionarily relevant circumstances will make very different choices than other aggregations of individuals under other evolutionarily relevant circumstances. Understanding such differences could allow for more fine-tuned understanding of decision-making than the assumption that individual differences are arbitrary. 
Economic psychologists have generated a host of findings that challenge assumptions of classical economic models, inspired by demonstrations such as Kahneman and Tversky's (1979) findings that slight variations in decision frame can lead to very different evaluations of mathematically identical problems. But diverse demonstrations of immediately suboptimal decisions leaves unanswered the deeper question is what exactly makes for a "rational" decision (c.f. Funder, 1987; Haselton \& Buss, 2000; Haselton \& Nettle, 2006; Krueger \& Funder, 2004). The classical view of rationality as the maximization of expected satisfaction cannot explain the way that most people make most of their decisions-and may not even explain the typical economist's decisions in important everyday contexts. Viewed from an evolutionary perspective, people generally make decisions according to a set of underlying decision-rules that, on average, would have resulted in fitness benefits in typical ancestral human groups. In this sense, human decision making exhibits deep rationality.

\section{Acknowledgments}

Much of the research discussed in this paper was supported by grants from the National Institute of Mental Health (MH064734) and National Science Foundation (0642873) to Douglas Kenrick and Steven Neuberg. Vladas Griskevicius thanks the National Science Foundation for a Graduate Research Fellowship. We also thank Joachim Krueger and two anonymous reviewers for the their helpful suggestions on an earlier draft of this paper.

\section{References}

Ackerman J, Kenrick DT. The costs of benefits: Help-refusals highlight key trade-offs of social life. Personality \& Social Psychology Review 2008;12:118-140. [PubMed: 18453475]

Ackerman J, Kenrick DT, Schaller M. Is friendship akin to kinship? Evolution \& Human Behavior. 2008

Ackerman J, Shapiro JR, Neuberg SL, Kenrick DT, Schaller M, Becker DV, Griskevicius V, Maner JK. They all look the same to me (unless they're angry): From out-group homogeneity to out-group heterogeneity. Psychological Science 2006;17:836-840. [PubMed: 17100781]

Agosta, WC. Chemical communication. New York: Scientific American; 1992.

Alcock, John. Animal behavior: An evolutionary approach. 8th. Sunderland, MA: Sinauer Associates; 2005.

Aktipis, CA.; Kurzban, R. Is Homo economicus extinct?: Vernon Smith, Daniel Kahneman and the Evolutionary Perspective. In: Koppl, R., editor. Advances in Austrian economics. Vol. 7. Elsevier; Amsterdam: 2004. p. 135-153.

Arias E. United States life tables, 2000. National Vital Statstics Report 2002;51:1-38.

Barrett HC, Kurzban R. Modularity in cognition: Framing the debate. Psychological Review 2006;113(3):628-647. [PubMed: 16802884]

Baumeister RF, Sommer KL. What do men want? Gender differences and two spheres of belongingness. Psychological Bulletin 1997;122:38-44. [PubMed: 9204778]

Becker DV, Kenrick DT, Neuberg SL, Blackwell KC, Smith DM. The confounded nature of angry men and happy women. Journal of Personality and Social Psychology 2007;92:179-190. [PubMed: 17279844]

Becker, GS. A treatise on the family. Cambridge, MA: Harvard University Press; 1981.

Bergstrom TC. Economics in a Family Way. Journal of Economic Literature 1996;34:1903-1934.

Bronfenbrenner, M.; Sichel, W.; Gardner, W. Economics. 3rd. Boston: Houghton Mifflin; 1990.

Burnstein E, Crandall C, Kitayama S. Some neo-Darwin decision rules for altruism: Weighing cues for inclusive fitness as a function of the biological importance of the decision. Journal of Personality and Social Psychology 1994;67:773-789.

Buss DM, Larsen RJ, Westen D, Semmelroth J. Sex differences in jealousy: Evolution, physiology, and psychology. Psychological Science 1992;3:251-255.

Cialdini, RB. Indirect tactics of image management: Beyond basking. In: Giacalone, RA.; Rosenfeld, P., editors. Impression management in the organization. Hillsdale, NJ: Erlbaum; 1989. p. 45-56. 
Clark MS, Mills J, Powell MC. Keeping track of needs in communal and exchange relationships. Journal of Personality and Social Psychology 1986;51:333-338. [PubMed: 3746615]

Cosmides, L.; Tooby, J. Cognitive adaptations for social exchange. In: Barkow, Jerome H.; Cosmides, L.; Tooby, J., editors. The adapted mind. Oxford: Oxford University Press; 1992. p. 163-228.

Dijkstra P, Buunk BP. Jealousy as a function of rival characteristics: An evolutionary perspective. Personality and Social Psychology Bulletin 1998;24:1158-1166.

Eatwell, J.; Newgate, M.; Newman, P., editors. The new palgrave: A dictionary of economics. London: Palgrave Macmillan; 1987.

Erev I, Cohen BL. Verbal versus numerical probabilities: Efficiency, biases, and the preference paradox. Organizational Behavior and Human Decision Processes 1990;45:1-18.

Ermer E, Cosmides L, Tooby J. Relative status regulates risky decision-making about resources in men: Evidence for the co-evolution of motivation and cognition. Evolution and Human Behavior. in press.

Fiske AP. The four elementary forms of sociality: Framework for a unified theory of social relations. Psychological Review 1992;99:689-723. [PubMed: 1454904]

Funder DC. Errors and mistakes: Evaluating the accuracy of social judgment. Psychological Bulletin 1987;101:75-90. [PubMed: 3562704]

Gandolfi, AE.; Gandolfi, AS.; Barash, DP. Economics as an evolutionary science: From utility to fitness. Piscataway, NJ: Transaction; 2002.

Gangestad SW, Simpson JA. On the evolutionary psychology of human mating: Trade-offs and strategic pluralism. Behavioral and Brain Sciences 2000;23:573-587. [PubMed: 11301543]

Gangestad SW, Garver-Apgar CE, Simpson JA, Cousins AJ. Changes in women's mate preferences across the ovulatory cycle. Journal of Personality and Social Psychology 2007;92:151-163. [PubMed: 17201549]

Garcia J, Koelling RA. Relation of cue to consequence in avoidance learning. Psychonomic Science 1966;4:123-124.

Gigerenzer, G. Adaptive thinking: Rationality in the real world. New York: Oxford University Press; 2000.

Gigerenzer, G.; Selten, R. Bounded Rationality. Cambridge: The MIT Press; 2002.

Green L, Myerson J. A discounting framework for choice with delayed and probabilistic rewards. Psychological Bulletin 2004;130:769-792. [PubMed: 15367080]

Griskevicius V, Cialdini RB, Kenrick DT. Peacocks, Picasso, and parental investment: The effects of romantic motives on creativity. Journal of Personality \& Social Psychology 2006;91:63-76. [PubMed: 16834480]

Griskevicius V, Goldstein N, Mortensen C, Cialdini RB, Kenrick DT. Going along versus going alone: When fundamental motives facilitate strategic (non)conformity. Journal of Personality \& Social Psychology 2006;91:281-294. [PubMed: 16881765]

Griskevicius V, Tybur JM, Sundie JM, Cialdini RB, Miller GF, Kenrick DT. Blatant benevolence and conspicuous consumption: When romantic motives elicit strategic costly signals. Journal of Personality and Social Psychology 2007;93:85-102. [PubMed: 17605591]

Griskevicius V, Tybur JM, Gangestad SW, Perea E, Shapiro JR, Kenrick DT. Aggress to impress: Hostility as an evolved context-dependent strategy. Journal of Personality and Social Psychology. in press.

Griskevicius V, Goldstein NJ, Mortensen CR, Sundie JM, Cialdini RB, Kenrick DT. Fear and loving in Las Vegas: Evolution, emotion, and persuasion. Journal of Marketing Research. in press.

Gutierres SE, Kenrick DT, Partch JJ. Beauty, dominance, and the mating game: Contrast effects in self-assessment reflect gender differences in mate selection. Personality and Social Psychology Bulletin 1999;25:1126-1134.

Haselton MG, Buss DM. Error management theory: A new perspective on biases in cross-sex mind reading. Journal of Personality and Social Psychology 2000;78:81-91. [PubMed: 10653507]

Haselton MG, Nettle D. The paranoid optimist: An integrative evolutionary model of cognitive biases. Personality and Social Psychology Review 2006;10:47-66. [PubMed: 16430328]

Hill, K.; Hurtado, AM. Ache life history. New York: Aldine De Gruyter; 1996. 
Kahneman D, Tversky A. Prospect Theory: An Analysis of Decision under Risk. Econometrica 1979;XLVII:263-291.

Kahneman, D.; Tversky, A. Loss aversion in riskless choice: A reference dependent model. In: Kahneman, D.; Tversky, A., editors. Choices, values and frames. Cambridge: Cambridge University Press; 1991. p. 143-158.

Kaplan, HS.; Gangestad, SW. Life history theory and evolutionary psychology. In: Buss, DM., editor. Handbook of evolutionary psychology. Hoboken, NJ: John Wiley \& Sons; 2005. p. 68-95.

Kenrick, DT.; Delton, AW.; Robertson, T.; Becker, DV.; Neuberg, SL. How the mind warps: Processing disjunctions may elucidate ultimate functions. In: Forgas, JP.; Haselton, MG.; Von Hippel, W., editors. The evolution of the social mind: Evolution and social cognition. New York: Psychology Press; 2007. p. 49-68.

Kenrick DT, Keefe RC. Age Preferences in mates reflect sex differences in human reproductive strategies. Behavioral and Brain Sciences 1992;15:75-133.

Kenrick DT, Li NP, Butner J. Dynamical evolutionary psychology: Individual decision-rules and emergent social norms. Psychological Review 2003;110:3-28. [PubMed: 12529056]

Kenrick, DT.; Luce, CL. An evolutionary life-history model of gender differences and similarities. In: Eckes, T.; Trautner, HM., editors. The developmental social psychology of gender. Hillsdale, NJ: Erlbaum; 2000. p. 35-64.

Kenrick DT, Neuberg SL, Zierk KL, Krones JM. Evolution and social cognition: Contrast effects as a function of sex, dominance, and physical attractiveness. Personality \& Social Psychology Bulletin 1994;20:210-217.

Kenrick DT, Sadalla EK, Groth G, Trost MR. Evolution, traits, and the stages of human courtship: Qualifying the parental investment model. Journal of Personality 1990:97-116. Special Issue on Biological Approaches to Personality.

Kenrick, DT.; Sadalla, EK.; Keefe, RC. Evolutionary cognitive psychology: The missing heart of modern cognitive science. In: Crawford, CB.; Krebs, DL., editors. Handbook of evolutionary psychology: Ideas, issues, and applications. Mahwah, NJ: Lawrence Erlbaum Associates Publishers; 1998. p. 485-514.

Kenrick, DT.; Sundie, JM. Dynamical evolutionary psychology and mathematical modeling: Quantifying the implications of qualitative biases. In: Gangestad, Stephen W.; Simpson, Jeffry A., editors. The evolution of mind: Fundamental questions and controversies. New York, NY: Guilford Press; 2007.

Kenrick, DT.; Sundie, JM.; Kurzban, R. Cooperation and conflict between kith, kin, and strangers: Game theory by domains. In: Crawford, C.; Krebs, D., editors. Foundations of evolutionary psychology. Mahwah, NJ: Erlbaum; 2008.

Kenrick DT, Sundie JM, Nicastle LD, Stone GO. Can One Ever Be Too Wealthy or Too Chaste? Searching for Nonlinearities in Mate Judgment. Journal of Personality \& Social Psychology 2001;80:462-471. [PubMed: 11300579]

Kirby KN, Marakovic NN. Delay-discounting probabilistic rewards: Rates decrease as amounts increase. Psychonomic Bulletin and Review 1996;3:100-104.

Klein SB, Cosmides L, Tooby J, Chance S. Decisions and the evolution of memory: Multiple systems, multiple functions. Psychological Review 2002;109:306-329. [PubMed: 11990320]

Kreps, David M. A Course in microeconomic theory. Princeton, NJ: Princeton University Press; 1990.

Krueger JI, Funder DC. Towards a balanced social psychology: Causes, consequences, and cures for the problem-seeking approach to social behavior and cognition. Behavioral \& Brain Sciences 2004;27:313-376. [PubMed: 15736870]

Laham SM, Gonsalkorale K, von Hippel W. Darwinian grandparenting: Preferential investment in more certain kin. Personality and Social Psychology Bulletin 2005;31:63-72. [PubMed: 15574662]

Li NP, Bailey JM, Kenrick DT, Linsenmeier JA. The necessities and luxuries of mate preferences: ting the trade-offs. Journal of Personality \& Social Psychology 2002;82:947-955. [PubMed: 12051582] 
Li NP, Kenrick DT. Sex similarities and differences in preferences for short-term mates: What, whether, and why. Journal of Personality \& Social Psychology 2006;90:468-489. [PubMed: 16594832]

Li NP, Halterman RA, Cason MJ, Knight GP, Maner JK. The stress-affiliation paradigm revisited: Do people prefer the kindness of strangers or their attractiveness? Personality and Individual Differences 2008;44:382-391.

Li, YJ.; Griskevicius, V.; Kenrick, DT. The relative utility of gains and losses across different domains of social life. Arizona State University; 2008. Unpublished data

Little AC, Jones BC, DeBruine LM. Preferences for variation in masculinity in real male faces change across the menstrual cycle. Personality and Individual Differences 2008;45:478-482.

Maner JK, Kenrick DT, Becker DV, Robertson TE, Hofer B, Neuberg SL, Delton AW, Butner J, Schaller M. Functional Projection: How Fundamental Social Motives Can Bias Interpersonal Perception. Journal of Personality \& Social Psychology 2005;88:63-78. [PubMed: 15631575]

Maner, Jon K.; DeWall, C Nathan; Baumeister, Roy F.; Schaller, Mark. Does Social Exclusion Motivate Interpersonal Reconnection? Resolving The "Porcupine Problem". Journal of Personality and Social Psychology 2007;92:42-55. [PubMed: 17201541]

Maner JK, Gailliot MT, Rouby DA, Miller SL. Can't take my eyes off you: Attentional adhesion to mates and rivals. Journal of Personality and Social Psychology. 2007

Mas-Collel, Andreu; Whinston, Michael; Green, Jerry R. Microeconomic theory. New York: Oxford University Press; 1995.

Mellers BA, Hertwig R, Kahneman D. Do frequency representations eliminate conjunction effects? An exercise in adversarial collaboration. Psychological Science 2001;12:269-275. [PubMed: 11476091]

Neuberg, SL.; Kenrick, DT.; Maner, JK.; Schaller, M. From evolved motives to everyday mentation: Evolution, goals, and cognition. In: Forgas, J.; Williams, K., editors. Social motivation: Conscious and unconscious processes. New York: Cambridge University Press; 2004. p. 133-152.

Neuberg, SL.; Kenrick, DT.; Schaller, M. Evolutionary social psychology. In: Fiske, ST.; Gilbert, DT.; Lindzey, G., editors. Handbook of social psychology. 5th. New York: John Wiley \& Sons; 2009. In press

Öhman A, Mineka S. Fears, phobias, and preparedness: toward an evolved module of fear and fear learning. Psychology Review 2001;108:483-522.

Pinker, S. The language instinct. New York: Norton; 1994.

Png, I.; Lehman, D. Managerial economics. Malden, MA: Blackwell; 2007.

Roese N, Pennington GL, Coleman J, Janicki M, Li NP, Kenrick DT. Sex differences in regret: All for love or some for lust? Personality \& Social Psychology Bulletin 2006;32:770-780. [PubMed: 16648202]

Roney JR. Effects of visual exposure to the opposite sex: Cognitive aspects of mate attraction in human males. Personality and Social Psychology Bulletin 2003;29:393-404. [PubMed: 15273016]

Rozin P, Kalat JW. Specific hungers and poison avoidance as adaptive specializations of learning. Psychological Review 1971;78:459-486. [PubMed: 4941414]

Sagarin BJ, Becker DV, Guadagno RE, Nicastle LD, Millevoi A. Sex differences (and similarities) in jealousy: The moderating influence of infidelity experience and sexual orientation of the infidelity. Evolution and Human Behavior 2003;24:17-23.

Schaller, M.; Park, JH.; Kenrick, DT. Human evolution and social cognition. In: Dunbar, RIM.; Barrett, L., editors. The Oxford handbook of evolutionary psychology. Oxford UK: Oxford University Press; 2007. p. 491-504.

Schaller M, Park JH, Mueller A. Fear of the dark: Interactive effects of beliefs about danger and ambient darkness on ethnic stereotypes. Personality and Social Psychology Bulletin 2003;29:637649. [PubMed: 15272996]

Sherry DF, Schacter DL. The evolution of multiple memory systems. Psychological Review 1987;94:439-454.

Simon, H. Models of man, social and rational: Mathematical essays on rational human behavior in a social setting. New York: Wiley; 1957. A Behavioral Model of Rational Choice. 
Singh D. Adaptive significance of female attractiveness: Role of waist-to-hip ratio. Journal of Personality \& Social Psychology 1993;65:293-307. [PubMed: 8366421]

Soltis J. The signal functions of early infant crying. Behavioral \& Brain Sciences 2004;27:443-490. [PubMed: 15773426]

Sundén AE, Surette BJ. Gender differences in the allocation of assets in retirement savings plans. American Economic Review 1998;88:207-211.

Wilcoxon HC, Dragoin WB, Kral PA. Illness-induced aversions in rat and quail: Relative salience of visual and gustatory cues. Science 1971;171:826-828. [PubMed: 5541167]

Winterhalder, B. Risk and decision-making. In: Dunbar, R.; Barrett, L., editors. Oxford handbook of evolutionary psychology. Oxford: Oxford University Press; 2007.

Trivers, RL. Parental investment and sexual selection. In: Campbell, B., editor. Sexual selection and the descent of man: 1871-1971. Chicago: Aldine; 1972. p. 136-179.

Van Vugt M, De Cremer D, Janssen D. Gender differences in competition and cooperation: The male warrior hypothesis. Psychological Science 2007;18:19-23. [PubMed: 17362372]

Varian, H. Microeconomic analysis. New York: W.W. Norton; 1992.

Wang XT. Risk as reproductive variance. Evolution and Human Behavior 2002;23:35-57.

Wilcoxon, H.; Dragoin, E.; Kral, P. Illness-induced aversion in rats and quail. In: Seligman, MEP.;

Hager, JL., editors. Biological boundaries on learning. New York: Appleton-Century-Crofts; 1972.

Wilson M, Daly M. Competitiveness, risk-taking, and violence: The young male syndrome. Ethology and Sociobiology 1985;6:59-73.

Wilson M, Daly M. Do pretty women inspire men to discount the future? Proceedings of the Royal Society B 2004;271 4:177-179. [PubMed: 15058395] 


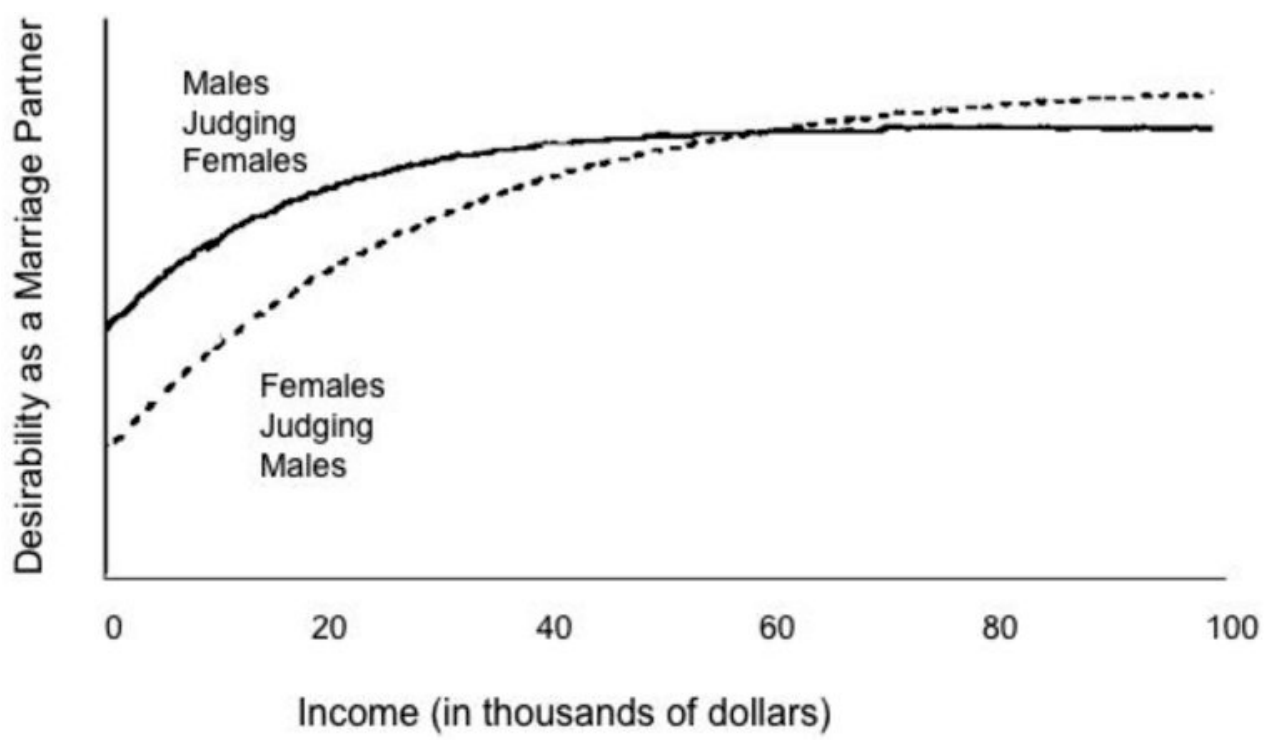

Figure 1.

Marginal utility of income in a mate varies with sex of the decision-maker. 


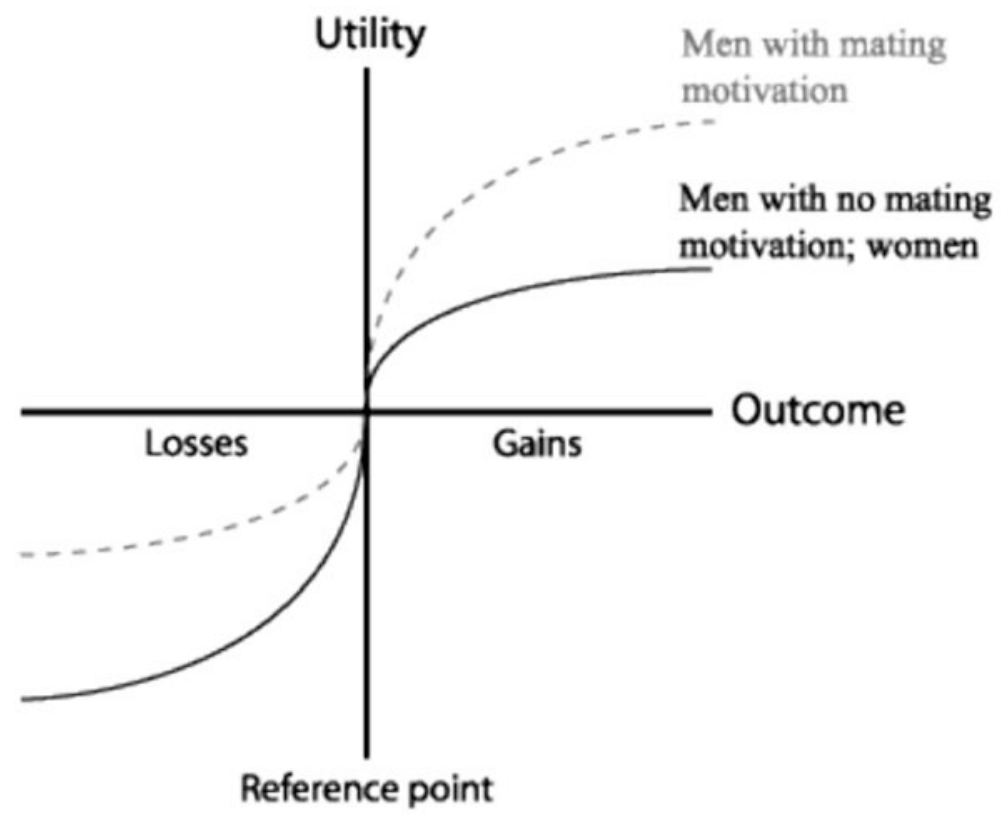

Figure 2.

Relative valuation of gains and losses. The dark line shows the typical function in which a given sized loss has more disutility than a comparable gain has utility. The lighter line is a hypothesized case in which these valuations might reverse (for men under mating motivation). 


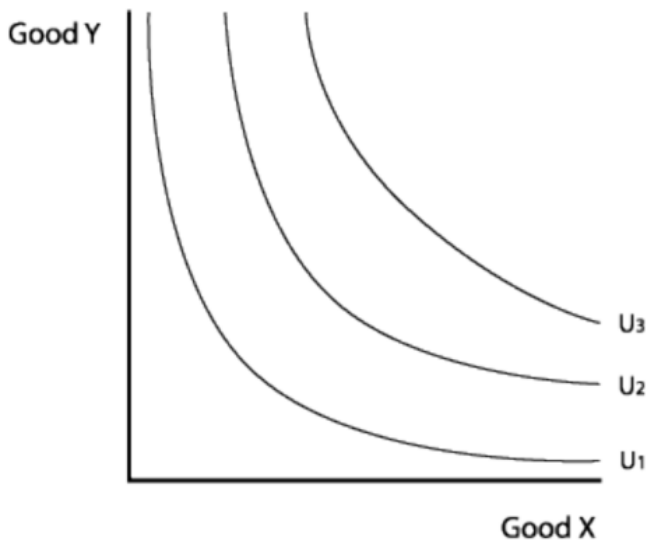

a. Two normal goods, $X$ and $Y$

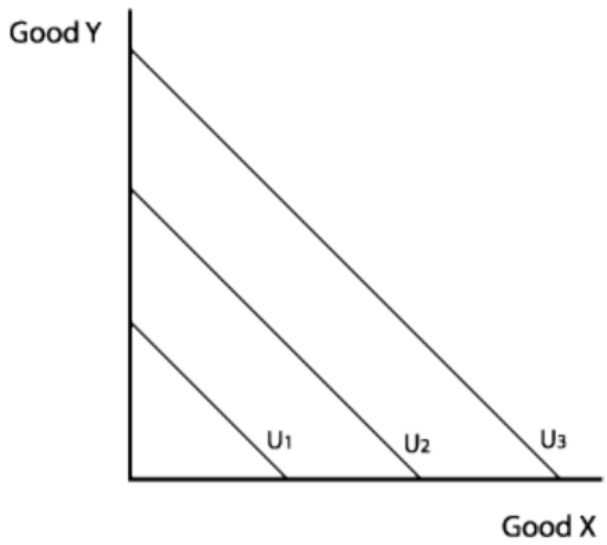

c. $X$ and $Y$ are perfect substitutes

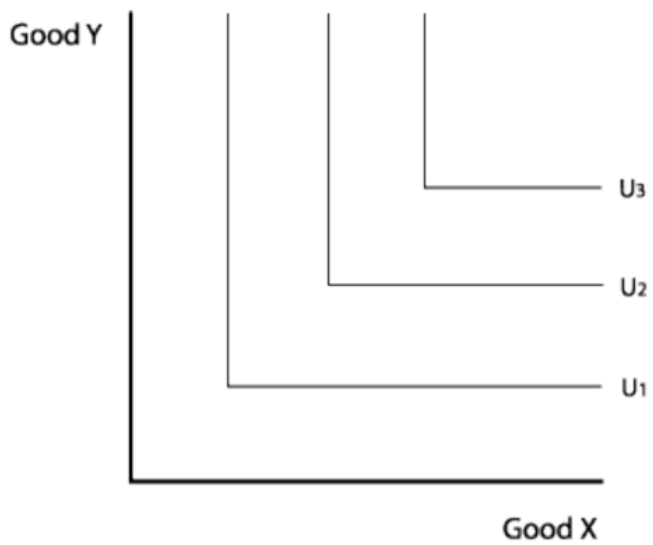

b. $X$ and $Y$ are perfect complements

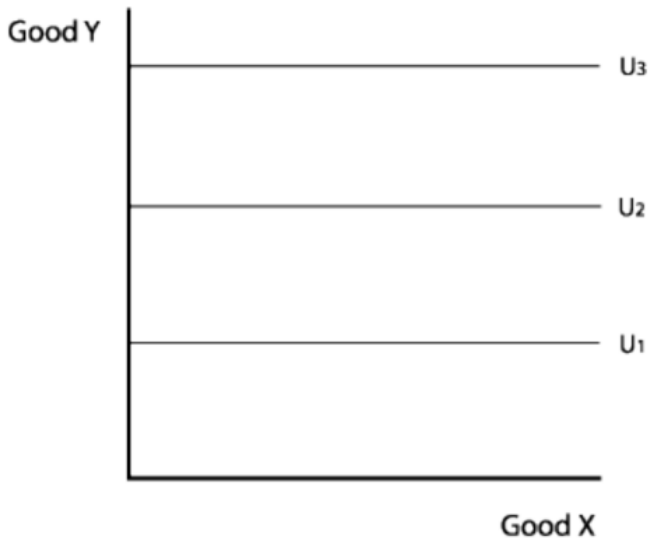

d. Only Good Y is valued

Figure 3.

Indifference curves of various types.

Note: The line U1, U2, and U3 desribe three increasingly desirable (and increasingly expensive) utility functions (utility level $\mathrm{U}_{3}>\mathrm{U}_{2}>\mathrm{U}_{1}$ ). For example, imagine that Good $\mathrm{Y}$ refers to brownies and Good X. Figure 3a depicts the state of affairs when a person prefers a combination of goods, as when increasing numbers of brownies without additional mochas would bring very little additional expected satisfaction (hence the convex shape in the curve). If $\mathrm{x}$ and $\mathrm{y}$ are perfect complements (e.g., left and right shoes), an increment in one without an increment in the other brings no increased utility (as in Figure 3b). If they are perfect substitutes (a mocha from one neighborhood Starbucks vs. another, for example), then the lines would not curve (as in figure $3 \mathrm{c}$ ). If the person only values one but not the other (loves brownies, but hates all coffee drinks, for example), then the line would runs parallel and flat with respect to the devalued commodity (as in Figure 3d). 


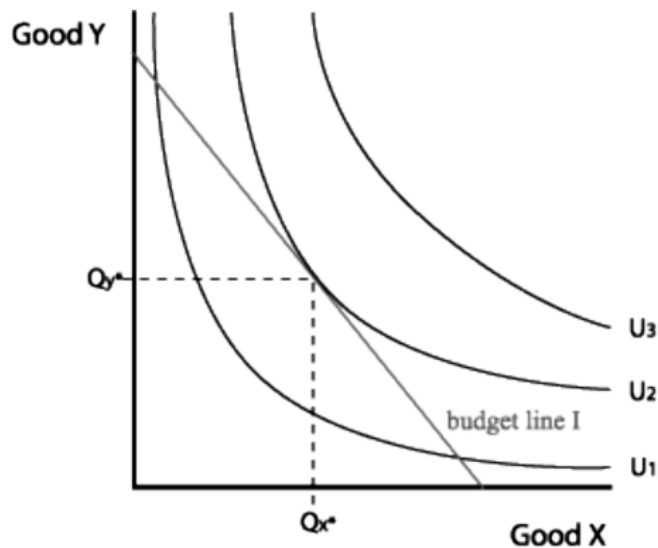

a. Preferences and budget jointly determine the consumption mix

Figure 4.

Indifference curves and budgets.

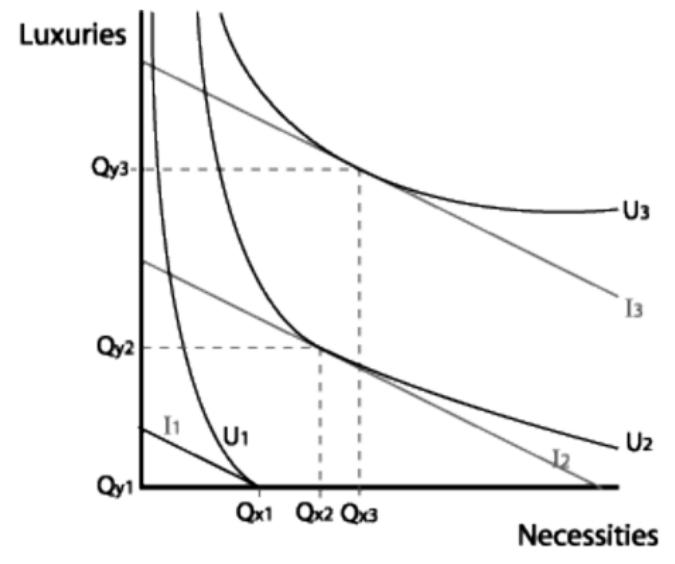

b. Necessities are favored at a low budget, luxuries are favored at a high budget 


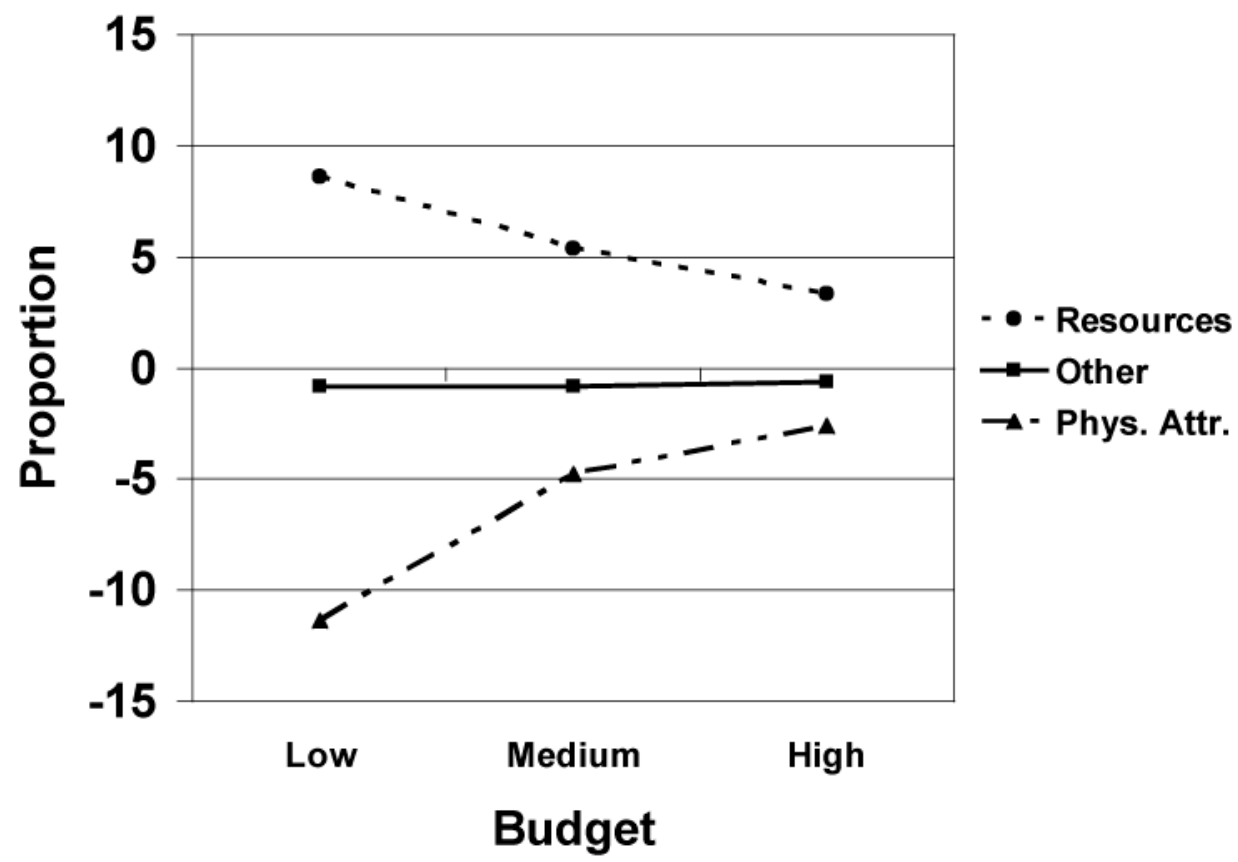

Figure 5.

Sex differences in proportion spent on physical attractiveness, status/resources, and other characteristics as a function of budget. Positive numbers denote females spending relatively more than males. Thus, on a low budget, women spent much more than men on resources and much less on attractiveness. This sex difference was reduced at high budgets.

Reproduced from Li et al. (2002). 
Table 1

Examples of behaviors and decisions associated with more or less utility in six broad social domains, and some decision biases associated with each domain.

\begin{tabular}{|c|c|c|c|}
\hline $\begin{array}{l}\text { Social domain and } \\
\text { associated social } \\
\text { goal }\end{array}$ & $\begin{array}{l}\text { Outcomes yielding relative } \\
\text { utility }\end{array}$ & Outcomes yielding relative disutility & Typical decision biases \\
\hline $\begin{array}{l}\text { Affiliation } \\
\text { Form and maintain } \\
\text { cooperative } \\
\text { alliances }\end{array}$ & $\begin{array}{l}\text { Proximity to alliance partners } \\
\text { Sharing resources equally } \\
\text { among alliance partners }\end{array}$ & $\begin{array}{l}\text { Social exclusion } \\
\text { Reciprocity violations }\end{array}$ & $\begin{array}{l}\text { Propensity to affiliate and conform when } \\
\text { feeling fearful } \\
\text { Sensitive cheating detection for } \\
\text { reciprocity violations. }\end{array}$ \\
\hline $\begin{array}{l}\text { Status } \\
\text { Gain and maintain } \\
\text { social status }\end{array}$ & $\begin{array}{l}\text { Dominating competitors } \\
\text { (relatively more for men) } \\
\text { Basking in reflective glory of } \\
\text { group members' achievements }\end{array}$ & $\begin{array}{l}\text { Deference to more powerful others } \\
\text { Public losses of relative status }\end{array}$ & $\begin{array}{l}\text { Risky status-yielding activities more } \\
\text { attractive for young unmated men and } \\
\text { less attractive for women. }\end{array}$ \\
\hline $\begin{array}{l}\text { Self-Protection } \\
\text { Protect oneself and } \\
\text { valued others from } \\
\text { threats }\end{array}$ & $\begin{array}{l}\text { Higher ratio of ingroup to } \\
\text { outgroup members when threats } \\
\text { salient. } \\
\text { Barriers to outgroup members } \\
\text { (e.g., walls, locks) }\end{array}$ & $\begin{array}{l}\text { Being in a numerical minority when } \\
\text { threat salient } \\
\text { Presence of threatening outgroup } \\
\text { members who are male and/or large. }\end{array}$ & $\begin{array}{l}\text { Rapid detection of anger in male (versus } \\
\text { female) faces } \\
\text { Enhanced memory of angry outgroup } \\
\text { male faces. }\end{array}$ \\
\hline $\begin{array}{l}\text { Mate Search } \\
\text { Attract desirable } \\
\text { mates }\end{array}$ & $\begin{array}{l}\text { For males judging females: } \\
\text { Cues to youth, health and } \\
\text { fertility } \\
\text { For females judging males: } \\
\text { Cues to investment as long- } \\
\text { term mates, social dominance } \\
\text { and physical symmetry in short- } \\
\text { term mates. }\end{array}$ & $\begin{array}{l}\text { Poor health, aging cues, assymmetry. } \\
\text { Conformity and deference to other } \\
\text { males among potential male mates. }\end{array}$ & $\begin{array}{l}\text { Males take more risks and resist } \\
\text { conformity when mating opportunities } \\
\text { are salient. } \\
\text { Females are more publicly (but not } \\
\text { privately) generous under mating } \\
\text { motivation. }\end{array}$ \\
\hline $\begin{array}{l}\text { Mate Retention } \\
\text { Retain and foster } \\
\text { long-term mating } \\
\text { bonds }\end{array}$ & $\begin{array}{l}\text { Communal sharing with } \\
\text { relationship partner, rather than } \\
\text { equality-based sharing } \\
\text { Investment in partner's } \\
\text { offspring }\end{array}$ & $\begin{array}{l}\text { Cues to emotional infidelity } \\
\text { (relatively more salient to females } \\
\text { judging males) } \\
\text { Cues to sexual infidelity (relatively } \\
\text { more salient to males judging females }\end{array}$ & $\begin{array}{l}\text { Attention by women to other physically } \\
\text { attractive women. } \\
\text { Attention by men to other socially } \\
\text { dominant men }\end{array}$ \\
\hline $\begin{array}{l}\text { Kin Care } \\
\text { Invest in offspring } \\
\text { and genetic relatives }\end{array}$ & $\begin{array}{l}\text { Benefits to offspring, and to } \\
\text { other relatives (discounted by } \\
\text { degree of relatedness) }\end{array}$ & $\begin{array}{l}\text { Threats to kin versus non-genetically } \\
\text { related alliance partners } \\
\text { Perceived favoritism of one's parent } \\
\text { towards one's siblings }\end{array}$ & $\begin{array}{l}\text { Grandparental investment highest by } \\
\text { grandmother in daughter's offspring } \\
\text { (tracking paternity certainty). }\end{array}$ \\
\hline
\end{tabular}

